\title{
Estratégia inovativa das firmas brasileiras: convergência ou divergência com as questões ambientais?
}

\author{
Julia Mello de Queiroz
}

Fundo Brasileiro para a Biodiversidade (Funbio), Rio de Janeiro (RJ), Brasil

Maria Gabriela von Bochkor Podcameni

Instituto Federal do Rio de Janeiro e Redesist/UFRJ, Rio de Janeiro (RJ), Brasil

Recebido: 10/07/2012 Versão Revisada (entregue): 30/05/2013 Aprovado: 17/06/2013

\begin{abstract}
Resumo
Com base nos dados da Pintec 2008, o artigo analisa as características e as estratégias inovativas das empresas brasileiras que realizaram inovações que reduziram os impactos no meio ambiente. Os dados evidenciam que a introdução de inovações ambientais (IA) está relacionada com o tamanho da firma e com a origem estrangeira do capital, ou seja, fatores que remetem à questão da importância da inserção internacional. Em relação às estratégias e aos esforços inovativos das empresas, os dados mostram que essas atividades são focadas nas estratégias que têm pouca ou nenhuma relação com as IA. Por outro lado, os fatores referentes à geração e difusão de conhecimento, aprendizado e fortalecimento das capacitaçōes apresentam significativa relação com as IA. Desse modo, os resultados mostram que as estratégias das firmas não convergem com a necessidade de se avançar rumo a um desenvolvimento menos agressivo ao meio ambiente.
\end{abstract}

Palavras-Chave | Inovação Ambiental; Pintec; Estratégias; Conhecimento

Código JEL | O30 


\title{
Brazilian Firms' Innovative Strategies: convergence or divergence with environmental issues?
}

\begin{abstract}
Based on Pintec 2008 data, the paper analyses the determinants of innovations that have reduced the environmental impact through the study of Brazilian firms' characteristics and innovative strategies. The results show that the introduction of environmental innovations (EI) is related to the firms' size and foreign capital ownership, that is, factors that lead to the importance of international insertion. Regarding the strategies and innovative efforts of firms, the data shows that these activities are focused on the determinants that have little or no relation with EI. On the other hand, factors related to the generation and diffusion of knowledge, learning and strengthening of competences have a significant relation with EI. In this sense, the results show that the firms' strategies do not converge with the need to move towards a development less aggressive to the environment.
\end{abstract}

KEYWORDS | Environmental Innovation; Pintec; Strategies; Knowledge

JEL-Code $\mid$ O30 


\section{Introdução}

Tendo em vista a crescente evolução no debate sobre o meio ambiente e dado o agravamento dos problemas ambientais, a conscientização sobre a sustentabilidade tem atingido um âmbito cada vez mais abrangente. Os agentes econômicos, tanto públicos quanto privados, em muitos casos têm buscado se adaptar às leis ambientais e metas internacionais de redução de poluição, sendo que algumas empresas já tentam compatibilizar a busca da eficiência produtiva e qualidade do produto com a conservação do meio ambiente (YOUNG et al. 2001). No entanto, muitas são as dificuldades enfrentadas por esses atores para se adaptarem ao recente cenário internacional.

Nesse contexto, a inovação aparece como um importante elemento para auxiliar os agentes a se adaptarem a essas novas responsabilidades. Mais especificamente, a inovação ambiental (IA) pode contribuir para que os processos produtivos tornem-se cada vez mais limpos por meio de produtos e processos que gerem menos danos ao meio ambiente. Desse modo, a IA pode ser um canal para gerar uma mudança tecnológica rumo a um novo paradigma tecnoeconômico, ou seja, pode caracterizar a emergência de um paradigma tecnoeconômico "verde" (FREEMAN, 1996; FORAY; GRUBLER, 1996).

No entanto, ainda existem poucos estudos que analisam as questôes relacionadas à IA e sua introdução por parte das firmas, pois, como o tema ainda é relativamente recente, ainda são poucos os surveys que analisam as inovações que geram menos danos ao meio ambiente. Diante disso, com base em estatísticas descritivas elaboradas a partir dos dados da Pesquisa de Inovação Tecnológica (Pintec) $2008^{1}$ para as empresas da indústria de transformação brasileira, o objetivo do artigo é verificar se existe uma convergência das estratégias inovativas das firmas com as questôes ambientais. Entende-se por estratégias inovativas as ações que envolvem a introdução de inovações por parte das empresas, tais como o tipo de atividade inovativa realizada (aquisição de máquinas e equipamentos, $\mathrm{P} \& \mathrm{D}$, etc.), o caráter da cooperação com parceiros e o tipo de financiamento. Além disso, as questôes ambientais são simplificadas na análise empírica como sendo a redução de impacto ambiental gerada pela inovação. ${ }^{2}$ Ou seja, busca-se analisar se as estratégias ino-

1 A Pesquisa de Inovação Tecnológica é produzida pelo IBGE com o objetivo de fornecer informações sobre a realização de atividades inovativas das empresas brasileiras com dez ou mais pessoas ocupadas nas indústrias extrativas, de transformação e de serviços selecionados. A Pintec 2008 disponibiliza dados para o período de 2006 a 2008. Até o momento foram publicadas quatro pesquisas: 2000, 2003, 2005 e 2008.

2 Sabe-se que as estratégias inovativas estão relacionadas a fatores muito mais sistêmicos, tais como contexto socioeconômico, questões organizacionais, institucionais, capacidade de absorção, acesso à informação, entre outros 
vativas adotadas pelas empresas brasileiras resultaram em diminuição do impacto ambiental. A partir disso, busca-se verificar quais estratégias inovativas estão mais relacionadas a essa redução.

Para atingir a finalidade do presente estudo, a seguir, procura-se definir o termo "inovação ambiental" e contextualizar a análise dos seus determinantes dentro da literatura neoschumpeteriana. Posteriormente, é verificada empiricamente a evolução do número de empresas que realizaram IA (2003-2008) e analisam-se, com base em estatísticas descritivas, as características das empresas e os fatores relacionados a esforço inovativo, estratégias de cooperação e fontes de financiamento que apresentam relação com as IA. Por fim, tem-se uma breve conclusão.

\section{Determinantes da inovação ambiental: uma análise a partir da teoria evolucionária}

Para que se possa fazer uma análise mais profunda dos fatores que influenciam a introdução de IA nas empresas, primeiramente deve-se definir tal conceito dentro da perspectiva evolucionária, levando em consideração a discussão de paradigmas econômicos.

Com o objetivo de compreender os padrões de mudança tecnológica, Dosi (1982) faz uma comparação entre a tecnologia e a ciência a partir da ideia de paradigma científico desenvolvido por Thomas Kuhn (1962) sobre padrões e modelos de solução de problemas. ${ }^{3}$ Nesse contexto, Dosi (1982) define a tecnologia como um conjunto das partes do conhecimento (tanto práticos quanto teóricos), que envolvem know-how, métodos, procedimentos e experiências bem ou mal sucedidas. A partir disso, o autor deixa claro o conceito de paradigma tecnológico: "We shall define a technological paradigm as 'model' and a 'pattern' of solution of selected technological problems based on selected principles derived from natural sciences and on selected material technologies" (DOSI, 1982, p. 152). O paradigma tecnológico define as direçôes das mudanças tecnológicas, ou seja, determina uma trajetória tecnológica,

(CASSIOLATO; LASTRES, 2008). Por outro lado, a simplificação das questões ambientais à redução de impacto ambiental como consequência das inovações também exclui uma análise mais abrangente do tema, que envolve questões de mudança do clima, mudança de hábitos de consumo, questões políticas, etc. Apesar de as autoras reconhecerem a abordagem sistêmica de inovação nas seções teóricas e os limites dos conceitos utilizados, a análise empírica do presente estudo não aborda todas essas esferas, em decorrência tanto da limitação dos dados quanto da abrangência do próprio artigo.

3 De acordo com Neves e Aguilar Filho (2012), o paradigma científico definido por Kuhn (1962) cria uma tradição de pesquisa em alguma área específica e envolve o fornecimento de um "guia" para o método de experimentação, uma base de procedimentos científicos para a solução de quebra-cabeças. 
que, por sua vez, constitui um conjunto de direções tecnológicas cujas fronteiras são definidas pelo paradigma.

Já o termo paradigma tecnoeconômico (TEP) é utilizado por Perez (2009) para se aproximar do conceito de paradigma econômico desenvolvido por Dosi (1982). Para aquele autor, o paradigma tecnológico é como um acordo tácito dos agentes envolvidos nessa dinâmica sobre qual seria o melhor produto, tecnologia ou serviço: "A paradigm is then a collectively shared logic at the convergence of technological potential, relative costs, market acceptance, functional coherence and other factors." (PEREZ, 2009, p 3). Um TEP gera uma significativa reorganização na estrutura social, econômica e institucional, aumentando a produtividade dos agentes ao determinar implicitamente a prática mais lucrativa, a melhor escolha de recursos, métodos e tecnologias, assim como a estrutura organizacional e as estratégias e modelos de negócios. Além disso, o TEP abre janelas de oportunidades para outras inovações e estimula a criação de novas tecnologias associadas. ${ }^{4}$

Com base na discussão sobre o processo de desenvolvimento e mudança tecnológica, Freeman (1996) aborda o tema da necessidade de se caminhar para uma sustentabilidade ambiental e define o conceito de paradigma tecnoeconômico "verde". como um novo padrão sustentável de crescimento, que envolve regulação, incentivos econômicos, mudanças institucionais e inovações tecnológicas. Esse paradigma verde, de acordo com Kemp e Soete (1990, p. 451), engloba mudanças relevantes nos processos produtivos em direção a uma maior sustentabilidade ambiental, ou seja, "new directions in which further growth and technological development might be ecologically sustainable".

Tomando como base a análise dinâmica do papel das inovações e a discussão de paradigmas, abre-se a possibilidade de analisar as questóes que envolvem inovação e meio ambiente dentro da teoria evolucionária, que possui uma visão também dinâmica do processo de desenvolvimento econômico. Para isso, deve-se definir o conceito de IA utilizado como base para as análises do presente trabalho.

A IA não pode ser definida pelo seu impacto ambiental absoluto, mas deve ser pensada em referência a tecnologias alternativas; além disso, ela não pode ser reduzida a uma resposta única e direta à regulação, devendo resultar de um complexo processo interativo (OLTRA, 2008). Dessa forma, a IA pode ser definida de acordo com as seguinte descrições:

4 Sabe-se que essa discussão é mais extensa e complexa do que o descrito aqui. No entanto, essa breve apresentação é suficiente para a compreensão do presente artigo. Para mais detalhes, ver Dosi (1982) e Perez (2009). 
The production, assimilation or exploitation of a product, production process, service or management or business methods that is novel to the organization (developing or adopting it) and which results, throughout its life cycle, in a reduction of environmental risk, pollution and other negative impacts of resources use (including energy use) compared to relevant alternatives. (MEI REPORT, 2008 apud OLTRA, 2008, p. 5).

Environmental innovation can be defined as innovation that occurs in environmental technologies or processes that either control pollutant emissions or alter the production processes to reduce or prevent emissions. (STERN, 2007, p. 352)

Portanto, a IA é basicamente uma inovação que reduz ou elimina os impactos ambientais negativos causados por determinada empresa. Deve-se ressaltar que o termo ecoinovação também é utilizado para definir inovações que reduzem os impactos ambientais em comparação com tecnologias alternativas (RENNINGS, 2000; ANDERSEN, 2004; KEMP e ANDERSEN, 2004, KEMP e PEARSON, 2007; FOXON e ANDERSEN, 2009). O Environmental Technology Action Plan (ETAP) da União Europeia, por exemplo, utiliza o termo ecoinovação para sinalizar o desenvolvimento de políticas tecnológicas em consonância com as questôes ambientais, com o objetivo de aumentar a competitividade da região nessa área de inovaçôes que diminuem as pressóes sobre o meio ambiente. ${ }^{5} \mathrm{O}$ documento define ecoinovação da seguinte maneira:

all technologies whose use is less environmentally harmful than relevant alternatives. They encompass technologies and processes to manage pollution (e.g. air pollution control, waste management), less polluting and less resource-intensive products and services and ways to manage resources more efficiently (e.g. water supply, energysaving technologies). (EUROPEAN COMMISSION, 2004, p. 2).

A literatura também apresenta tipos de ecoinovação. Kemp e Foxton (2007) ${ }^{6}$ dividem as IA em tecnologias ambientais, inovaçōes organizacionais, inovação de produto ou serviço e inovaçôes de sistemas de produção e consumo. Outra análise interessante é feita pela OCDE no relatório Sustainable manufacturing and

5 Disponível em: <http://ec.europa.eu/environment/ecoap/about-action-plan/etap-previous-action-plan/index en.htm>

6 Relatório Typology of eco-innovation (projeto Measuring Eco-innovation - European Project). Disponível em: <http:// www.merit.unu.edu/MEl/>. 
eco-innovation: framework, practices and measurement de 2009, no qual as IA são separadas em controle da poluição, produção mais limpa, ecoeficiência, abordagem do ciclo de vida, produção em "closed-loop" e ecologia industrial.

Apesar de os conceitos de ecoinovação e IA serem utilizados muitas vezes como sinônimos (RENNINGS, 2000), o presente artigo optou por utilizar o termo IA para dar continuidade a uma agenda de pesquisa desenvolvida pelas autoras utilizando trabalhos como Oltra (2008), Lustosa (1999), entre outros.

A IA pode ser desenvolvida de maneira intencional e premeditada pela empresa ou mesmo acidental. Além disso, muitos dos impactos ambientais positivos ocorrem durante toda a vida útil do produto, o que aumenta a dificuldade para a mensuração da IA (ARUNDEL et al., 2007).

A distinção entre IA e inovação que não gera redução dos impactos ambientais não é tão nítida quanto se imagina. Em muitos casos, a IA é apenas uma consequência da atividade inovativa das empresas. Ao realizarem inovações que não tenham claramente objetivos ambientais, mas visem apenas eficiência produtiva, as firmas acabam diminuindo custos por meio da redução do uso de matéria-prima e energia. Como ressalta Oltra (2008, p. 4):

But whatever the term, environmental innovations are generally distinguished from innovation in general and so studied separately. Why such a distinction? Is it just because environmental innovations have initially been studied by researchers coming from the field of environmental economics? Or is it motivated by a real specificity of environmental innovations which calls for specific concepts and analytical tools? The answer to these questions requires a clarification of the definition of environmental innovations, as well as thorough analysis of their properties and determinants.

Como a IA e a inovação não ambiental têm muitos elementos em comum por serem, a priori, processos inovativos, pode-se argumentar que elas não são totalmente separáveis. Muitas vezes, as empresas não percebem a IA de maneira adequada, pois não fazem inovaçôes que tenham objetivos diretos de redução dos impactos ambientais. Assim, o conceito de IA pode ser muito mais ligado à estratégia inovativa geral da empresa do que propriamente às questóes ambientais. William e Markusson (2002) criticam essa distinção entre inovação ambiental e não ambiental e afirmam que o aspecto ambiental das inovaçôes deve ser considerado dentro do contexto que elas são inseridas. 
Diante dessas críticas ao conceito e ao recorte da IA, pode-se argumentar que o objetivo do artigo de analisar a convergência ou divergência das estratégias inovativas com a questão ambiental torna-se uma tarefa bastante complicada. A operacionalidade do conceito é baixa e a maneira de encaixá-lo nos dados não é direta. Portanto, será feito um esforço para analisar se as empresas que realizaram inovaçóes que tiveram redução dos impactos ambientais têm um parâmetro diferenciado de estratégias, levando em conta as limitaçôes que o conceito de IA apresenta.

Apesar desses limites, de acordo com a literatura, algumas especificidades das inovações que reduzem os impactos ambientais podem ser destacadas. Uma das suas principais características está relacionada à geração de uma dupla externalidade no seu processo de criação e difusão. A IA não somente gera os spillovers típicos das atividades de criação e difusão de conhecimento, mas também acarreta impactos ambientais positivos. Além disso, as incertezas que envolvem o processo inovativo são ampliadas pelo fato de as IA ainda serem relativamente um assunto recente. Como as empresas utilizam suas rotinas e seu conhecimento tácito no processo inovativo, pode-se afirmar que esse acúmulo de conhecimento no que tange à IA ainda é incipiente. Assim, as firmas têm informação incompleta e não conseguem identificar o potencial da IA.

Dessa forma, apesar dos obstáculos à criação de IA devido às falhas de mercado, existem diversas motivações para a geração deste tipo de inovação. Primeiramente, a IA não é induzida somente pela necessidade de redução de custos e lucro individual das firmas. A pressão consumidora exerce importante papel nesse cenário (FERRAZ; SEROA DA MOTTA, 2001), pois o consumo consciente tem crescido significativamente (DINIZ et al., 2010). Diversos bancos já têm critérios de sustentabilidade para liberarem linhas de crédito (YOUNG et al., 2009) e empresas ambientalmente responsáveis passam a ser mais cotadas no mercado.

Além desses fatores, Lustosa (1999) afirma que a estrutura de mercado tem forte influência sobre as IA. Normalmente, pequenas e médias empresas possuem menos informações sobre os problemas ambientais e sobre as tecnologias disponíveis, além de se depararem com dificuldades de acesso ao financiamento e às importaçôes. Por outro lado, empresas maiores normalmente têm métodos de controle e fiscalização ambiental, pois são mais "visíveis" diante dos órgãos reguladores.

Por causa da dupla externalidade da IA, a regulação aparece como um dos seus principais determinantes, pois este tipo de inovação pode gerar um sinal para as empresas de possíveis ineficiências de recursos, criando uma possibilidade de melhora tecnológica. Desse modo, a regulação pode gerar vantagens competitivas 
para as firmas que tenham se adaptado mais rápido às regras (vantagens de ser um first-mover), como aumento do market-share e incremento da capacidade de learning-by-doing, o que caracterizaria uma situação win-win tal qual definida pela hipótese de Porter (PORTER; VAN DER LINDE, 1995), na qual a IA é capaz de gerar benefícios econômicos e ambientais ao mesmo tempo.

No entanto, não é toda regulação que gera soluçôes inovativas eficientes, pois seus resultados dependem do tipo do instrumento regulatório adotado, além do contexto e da estrutura na qual ele é inserido. Como muitas vezes a regulação induz a inovaçôes do tipo end-of-pipe (ou tratamento de final de linha), ela pode não ser um driver de soluçôes tecnológicas e organizacionais integradas (ARUNDEL et al., 2007), pois não torna a estrutura do processo produtivo mais limpa. Outra importante crítica é que a intenção de redução futura de custos decorrente da introdução de novas tecnologias pode não se concretizar. Por outro lado, o governo deve ter amplo conhecimento dos problemas ambientais provenientes de certa atividade econômica para que a regulação seja eficiente (JAFFE et al., 2004). Além disso, caso seja direcionada a uma determinada tecnologia e não ao nível de emissão, a regulação pode inibir processos inovativos mais eficientes ambientalmente.

Nesse contexto, Romeiro e Salles Filho (1997) corroboram esse argumento e afirmam que a introdução de IA não pode ser explicada somente pela necessidade de internalização dos custos derivados da regulação, mas também pela vantagem advinda da percepção de oportunidades tecnológicas. O desenvolvimento e a introdução da IA ocorrem quando o contexto competitivo no qual a firma opera passa a assimilar o meio ambiente como variável relevante. $\mathrm{O}$ resultado é que as empresas também começam a considerar as questôes ambientais para suas rotinas e estratégias. Nessa mesma direção, Corazza (1996) afirma que a questão ambiental passa a integrar as estratégias inovativas no momento que essa nova esfera representa oportunidades para criar competências relacionadas a vantagens competitivas, como a expansão na participação no mercado ou mesmo abertura de novos. Ou seja, a introdução ou não das IA também depende das características, estratégias e especificidades de cada firma, o que inclui sua capacidade de resposta a determinado instrumento regulatório (REHFELD et al., 2007).

Em relação às estratégias das empresas, Mazzanti e Zoboli (2006) afirmam que o pertencimento a algum tipo de grupo ou rede aparece como um driver positivo das IA, o que sugere que "economias horizontais de escala" e estratégias cooperativas são mais relevantes do que economias internas de escala. Assim, o envolvimento dos setores e empresas com as IA está relacionado não somente à sua capacidade 
inovativa em geral, mas também à sua relação com as demais empresas e com o meio ambiente:

Summing up, the 'innovative driver box' may consist of the following main factors: (i) firm involvement in groups and networking activities, (ii) 'innovative oriented' industrial relations and a less hierarchical organization [...] (iii) environmental (policy related) costs, (iv) $R \& D$, and final but not less important, (v) voluntary environmental schemes (MAZZANTI; ZOBOLI, 2006, p. 21).

$\mathrm{Na}$ tentativa de comparar a natureza dos determinantes da IA e da não ambiental, Horbach (2006) conclui que atividades de P\&D são mais importantes para IA do que para inovaçôes comuns, o que pode ser explicado pelo fato de que tecnologias mais limpas requerem uma mudança no processo produtivo, o que, por sua vez, exige altos inputs de recursos. Ele ainda evidencia que a redução de custos e a regulação são importantes determinantes para a IA, mas são menos relevantes para outras inovaçôes. Por fim, medidas organizacionais e estratégicas desencadeiam os dois tipos de inovação, mas são mais significantes para IA, confirmando uma das hipóteses de Porter (PORTER; VAN DER LINDE, 1995), na qual a introdução de mudanças na estrutura organizacional é relevante para IA.

Nessa mesma linha de raciocínio, Frondel et al. (2004) evidenciam que incentivos internos à empresa (como o fortalecimento da imagem corporativa) e o rigor da implementação e do design de políticas ambientais podem estimular as decisões das firmas em direção às IA. Desse modo, os autores sugerem que se deve dar mais prioridade a um mix de instrumentos de políticas ambientais dentro das firmas do que a um único elemento.

Em relação às empresas brasileiras, destacam-se estudos que analisam as características e o comportamento competitivo daquelas que introduzem IA. Segundo Lustosa (1999), as firmas que mais investem em P\&D também são as mesmas que modificaram seus processos produtivos por questōes ambientais. Podcameni (2007) corrobora alguns resultados de Lustosa (1999) e adiciona questões sobre competitividade, enfatizando que empresas que realizaram IA apresentam melhor desempenho competitivo dos que as demais firmas inovadoras.

\section{Evolução das empresas que realizaram inovações ambientais}

Antes de aprofundar na análise empírica acerca das características e das estratégias inovativas das empresas que realizaram IA, a presente seção aborda o crescimento 
do número de empresas da indústria de transformação brasileira que realizaram essas inovações.?

Com base em estatísticas descritivas da Pesquisa de Inovação Tecnológica (Pintec) de 2003, 2005 2008, utilizaram-se, como proxies de IA, variáveis que estão relacionadas às questôes ambientais: redução do consumo de matéria-prima; redução do consumo de energia; redução do consumo de água; e implementação de técnicas em gestão ambiental. Sabe-se que essas variáveis muitas vezes estão relacionadas à estratégia de otimização das firmas e, por isso, podem não ser decorrentes diretamente da responsabilidade ambiental das mesmas. No entanto, para analisar a evolução da introdução das IA entre 2003 e 2008, foi necessário utilizar tais proxies, pois são as únicas disponíveis nesse horizonte temporal. Como será descrito na adiante na metodologia, a Pintec somente inclui uma pergunta relacionada diretamente à questão ambiental na publicação de 2008. Desse modo, a metodologia empregada considera que as empresas que realizaram IA relataram importância média ou alta para as três primeiras variáveis. A resposta para a pergunta sobre gestão ambiental já é binária. A Tabela 1apresenta os dados referentes a essa análise. ${ }^{8}$

Observa-se que o percentual de empresas da indústria que geraram impactos positivos no meio ambiente tem uma tendência de crescimento significativa nos anos analisados, com destaque para a redução de matéria-prima e introdução de técnicas de gestão ambiental. Também é possível perceber que houve uma especialização em IA nos anos analisados. O Gráfico 1 evidencia esse comportamento, mostrando a evolução do percentual das empresas que realizaram inovações de forma geral e daquelas que fizeram algum tipo de IA (com base no total de firmas da indústria de transformação), tomando o ano 2003 como base.

7 Deve-se ressaltar que o presente artigo não analisa empiricamente as questões referentes à regulação e IA por não caber no escopo do trabalho. Para mais detalhes sobre o tema, ver Podcameni et al. (2011).

8 É importante ressaltar os limites para mensurar a questão da sustentabilidade nos processos inovativos. Como esses processos são sistêmicos, amplos e envolvem diversos atores, os indicadores não captam as especificidades da dinâmica inovativa. Essa crítica torna-se mais acentuada à medida que são utilizadas metodologias desenvolvidas pela OCDE para mensuração da atividade inovativa nos países em desenvolvimento, como o Brasil. Diferentemente dos países da OCDE que são caracterizados por estruturas produtivas mais homogêneas, o Brasil possui uma significativa heterogeneidade setorial e regional (CASSIOLATO et al., 2008). Desse modo, a utilização de indicadores "importados" não captam as especificidades locais, regionais e setoriais das atividades inovativas, como as pequenas mudanças nos produtos que podem ter impactos relevantes somente no longo prazo, circulação de conhecimento, etc. Para mais detalhes sobre a limitação de utilização desses indicadores, ver Cassiolato et al. (2008). Além disso, pela complexidade do conceito de sustentabilidade, esses indicadores não refletem a visão sistêmica que também caracteriza a esfera ambiental. 
TABELA 1

Empresas da indústria de transformação que realizaram IA, segundo tipos de inovações

Brasil - 2003-2008

Em porcentagem

\begin{tabular}{|c|c|c|c|c|c|c|}
\hline \multirow[t]{2}{*}{$\begin{array}{c}\text { Inovações } \\
\text { ambientais }\end{array}$} & \multicolumn{3}{|c|}{$\begin{array}{l}\text { Sobre o total de } \\
\text { empresas da indústria de } \\
\text { transformação }\end{array}$} & \multicolumn{3}{|c|}{$\begin{array}{l}\text { Sobre o total de empresas } \\
\text { inovadoras da indústria de } \\
\text { transformação }\end{array}$} \\
\hline & 2003 & 2005 & 2008 & 2003 & 2005 & 2008 \\
\hline Gestão ambiental & 4,5 & 5,2 & 10,8 & 13,4 & 15,2 & 28,0 \\
\hline $\begin{array}{l}\text { Redução de matéria- } \\
\text { prima }\end{array}$ & 4,4 & 6,4 & 9,4 & 13,2 & 18,6 & 24,3 \\
\hline Redução de energia & 3,9 & 5,3 & 8,7 & 11,6 & 15,4 & 22,4 \\
\hline $\begin{array}{l}\text { Redução de água } \\
\text { Inovação de produto }\end{array}$ & 1,4 & 2,3 & 4,4 & 4,3 & 6,6 & 11,3 \\
\hline e processo & 33,3 & 34,4 & 38,6 & 100,0 & 100,0 & 100,0 \\
\hline
\end{tabular}

Fonte: IBGE. Pesquisa de Inovação Tecnológica - Pintec 2003, 2005 e 2008. Elaboração das autoras.

\section{GRÁFICO 1}

Crescimento do percentual das empresas da indústria de transformação que realizaram inovações de produto e/ou processo e IA Brasil - 2003-2008

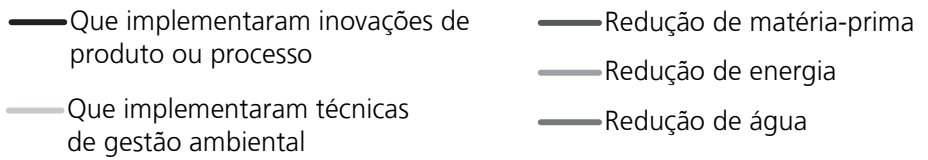

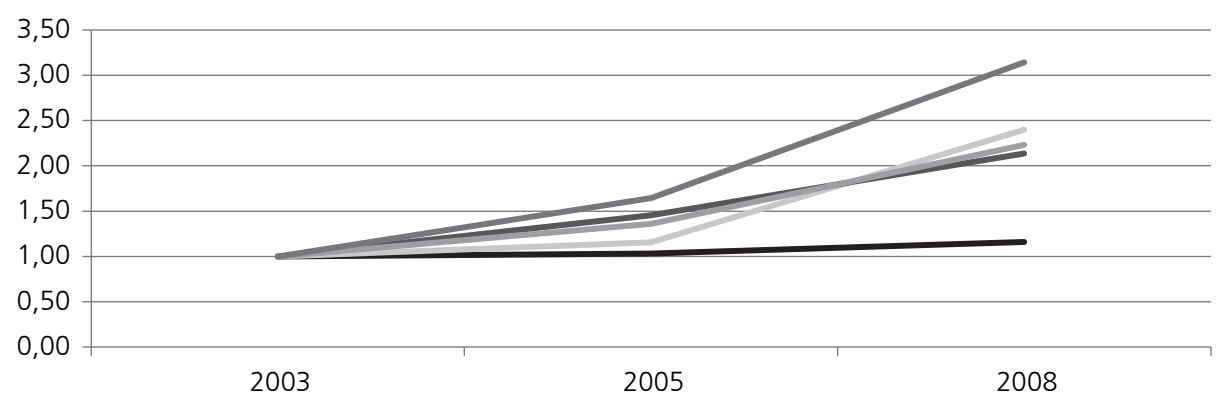

Fonte: IBGE. Pesquisa de Inovação Tecnológica - Pintec 2003, 2005 e 2008. Elaboração das autoras. 
Com base no Gráfico 1, percebe-se que a porcentagem de empresas da indústria que realizaram inovações de produto e/ou processo aumentou muito pouco quando comparada com aquelas que implementaram IA. Por exemplo, enquanto a porcentagem de firmas que desenvolveram alguma inovação que gerou redução do consumo de água aumentou mais de três vezes no período estudado, a proporção daquelas que inovaram em produto e/ou processo de maneira geral cresceu muito pouco, o que evidencia que as empresas que realizaram IA estão ganhando espaço no total de empresas inovadoras.

A ampliação do número de firmas que realizaram inovações ambientais está relacionada com o aumento da relevância dessas questôes nos dias de hoje. No mundo todo, são nítidas as iniciativas de diversas empresas que desenvolveram IA por acreditarem na sustentabilidade ambiental, inserindo essa mentalidade nas suas estratégias (VINHA, 1999). Outras realizaram inovações que geraram redução de danos ambientais para serem mais bem vistas no mercado ou por conhecerem os ganhos de competitividade com esse tipo de produto e processo (LUSTOSA, 1999). Por outro lado, diversas empresas introduziram essas inovaçōes somente por uma estratégia de redução de custos (CORAZZA, 2003), que está ligada à diminuição desses insumos. Portanto, pode-se afirmar que essa tendência também se torna evidente na realidade das empresas brasileiras, que estão tentando entrar nessa "corrida verde".

Entretanto, deve-se lembrar que, apesar desse crescimento, ainda é muito pequeno o número de empresas que realizaram inovaçóes que geraram impactos positivos no meio ambiente. Para que a economia brasileira alcance níveis suficientes de diminuição da poluição e da degradação ambiental, faz-se necessário que as empresas insiram as questōes ambientais nas suas estratégias para que as inovações não tenham somente efeitos ambientais pontuais, mas gerem consequências positivas integradas, possibilitando uma mudança rumo a um paradigma mais verde.

\section{Características, esforço inovativo e estratégias das empresas que introduziram IA}

Com base nos dados da Pintec 2008, são analisados, nessa seção, as principais características, estratégias e o tipo de esforço inovativo das empresas que realizaram

9 Esse aumento do número de empresas com preocupação ambiental já ocorre antes mesmo de 2003, como pode ser verificado no trabalho de Barcellos et al. (2009). Nesse estudo, os autores mostram que os investimentos em controle ambiental das indústrias da amostra da PIA passaram de $R \$ 10,5$ bilhões, em 1997, para $R \$ 22,1$ bilhões, em 2002, alavancados pela indústria de transformação. Com os valores atualizados para 2002, esse crescimento foi de $83,9 \%$. 
inovações ambientais. $\mathrm{O}$ objetivo é verificar se existem diferenças em relação aos determinantes das IA e das demais inovações e, assim, identificar se as estratégias inovativas das firmas brasileiras são convergentes ou não com a questão ambiental. Deve-se ressaltar que o recorte escolhido e o modo restrito de tratar a IA empiricamente decorrem da utilização de uma base de dados limitada para se trabalhar com o tema inovação e meio ambiente.

\subsection{Metodologia}

Para analisar as características, o esforço inovativo e as estratégias das empresas que realizaram IA, primeiramente buscou-se identificar as perguntas da Pintec 2008 que mais se aproximassem do complexo conceito de inovação ambiental. Como foi visto na seção anterior, existem outras perguntas nos questionários da Pintec 2003, 2005 e 2008 que também questionam sobre fatores ligados ao meio ambiente, como redução do consumo de matéria-prima, energia e água. No entanto, essas perguntas estão muito relacionadas com a estratégia de otimização das empresas e, por isso, podem não estar diretamente conectadas às estratégias ambientais das mesmas.

Assim, optou-se por utilizar a questão 105 ("Permitiu reduzir o impacto sobre o meio ambiente" ${ }^{10}$ ) para captar a percepção das firmas sobre a redução da degradação ambiental como consequência das atividades inovativas. A partir daí, foi definida outra variável (RIA - redução do impacto ambiental) como uma nova proxy de IA para analisar as características das empresas que introduziram essas inovações e os elementos capazes de influenciar os agentes a introduzirem esse tipo de inovação.

Para fazer a análise comparativa das estratégias e esforço inovador das firmas da indústria de transformação que realizaram ou não IA, foram excluídas da amostra as empresas não inovadoras em produto e/ou processo. Entre as inovadoras, considerou-se que as firmas que realizaram RIA relataram importância média ou alta para a questão 105 e as que não realizaram declararam importância baixa ou não relevante. Assim, foram verificados os fatores que apresentaram relações com as IA a partir de associações nas estatísticas descritivas. ${ }^{11}$

Deve-se ressaltar que, quando se fala diretamente sobre redução dos impactos ambientais, as respostas dos representantes das empresas ao questionário da Pintec

\footnotetext{
10 Essa questão só foi introduzida na Pintec 2008.

11 Neste trabalho, optou-se por utilizar somente estatísticas descritivas como uma primeira análise dos dados. Trabalhos que incluem modelos econométricos e análises de variância, covariância e outros testes estão sendo desenvolvidos pelas autoras.
} 
podem ser superestimadas em decorrência da necessidade de afirmar a responsabilidade socioambiental das empresas nos dias de hoje. Além disso, como foi dito, a separação entre IA e inovação que não gera redução de impacto ambiental não é trivial. A IA pode ser considerada uma parte e/ou consequência da inovação, o que gera uma dificuldade de separar nitidamente investimento ambiental e não ambiental nos processos inovativos. ${ }^{12}$ Somam-se a isso os limites da Pintec em relação à captação tanto dos próprios processos inovativos quanto das questôes ambientais, ${ }^{13}$ o que evidencia ainda mais a amplitude do conceito discutido. Por outro lado, é importante ressaltar que a utilização de indicadores e proxies para IA é necessária, na medida em que é interessante comparar com os consensos existentes sobre a dinâmica inovativa. Além disso, empregar uma variável nova relacionada à questão ambiental pode gerar resultados robustos e extremamente relevantes para esse debate.

\subsection{Características}

Cerca de 33\% das empresas inovadoras da indústria de transformação declaram importância alta ou média para redução do impacto ambiental, ou seja, das 37.808 firmas inovadoras, 12.451 indicaram que suas inovaçōes reduziram o impacto ambiental. Esse resultado evidencia que uma parcela expressiva das empresas inovadoras já está atenta às questôes ambientais.

A Tabela 2 relaciona o capital controlador e o tamanho da empresa com a variável ambiental.

Enquanto apenas 32,6\% das empresas de capital nacional desenvolveram inovações RIA, entre aquelas de capital estrangeiro esse percentual sobre para 43,1\%. Ou seja, firmas de capital estrangeiro adotam, proporcionalmente, mais inovações relacionadas à questão ambiental.

Quanto maior o tamanho da empresa, maior o percentual de firmas que realizam IA. Para a variável RIA, 30,2\% daquelas com até 50 funcionários desenvolveram essa IA, percentual aumenta para $53,4 \%$ no caso das que possuem mais de 500 pessoas ocupadas. Esses resultados também confirmam, para 2008, as evidências apontadas por Podcameni (2007) para 2003, de que firmas de capital estrangeiro

\footnotetext{
12 Deve-se lembrar que o estudo não entra no debate sobre o que pode ou não ser considerado IA. Ao tomar como base a definição de IA descrita na segunda seção, as autoras utilizam a declaração das firmas na Pintec reconhecendo os limites dos dados e dos indicadores.

13 Como se sabe, pela Pintec não é possível verificar que tipo de IA foi implementado pela firma (end-of-pipe ou pollution prevention) e tampouco os tipos de benefícios gerados ao meio ambiente.
} 
e de maior porte introduziram mais IA, ${ }^{14}$ o que reflete a questão da inserção internacional e está de acordo com as características das inovações de maneira geral. Essas evidências convergem com a análise de Lustosa (1999), na qual a estrutura de mercado tem influência sobre as IA em decorrência das questôes relacionadas a informação, acesso a financiamento e reconhecimento dos benefícios da inserção ambiental nas suas estratégias.

TABELA 2

Distribuição das empresas da indústria de transformação que realizaram IA, por situação de redução do impacto ambiental, segundo capital controlador e tamanho da empresa

Brasil - 2008

\begin{tabular}{l|c|c|c}
\hline \multicolumn{1}{c}{$\begin{array}{c}\text { Capital controlador } \\
\text { tamanho da empresa }\end{array}$} & Sim & Não & Total \\
\cline { 2 - 4 } & & & \\
\hline Capital controlador & 43,1 & 56,9 & 100,0 \\
Estrangeiro & 32,6 & 67,4 & 100,0 \\
Nacional & 33,9 & 66,1 & 100,0 \\
Misto & & & \\
Tamanho & 30,2 & 69,8 & 100,0 \\
Até 50 pessoas ocupadas & 38,5 & 61,5 & 100,0 \\
De 50 a 250 pessoas ocupadas & 45,9 & 54,1 & 100,0 \\
De 250 a 500 pessoas ocupadas & 53,4 & 46,6 & 100,0 \\
Mais de 500 pessoas ocupadas & & & \\
\hline
\end{tabular}

Fonte: IBGE. Pesquisa de Inovação Tecnológica - Pintec 2008. Elaboração das autoras.

A relação entre tamanho da empresa e IA também é apontada por Barcellos et al. (2009), que analisam os investimentos ambientais a partir dos dados da Pesquisa Industrial Anual (PIA) para os anos de 1997 e 2002. Segundo os autores, a porcentagem de empresas da amostra que realizaram investimentos ambientais passou de 3,6\% para 4,9\%, no período estudado. Em 1997, o valor da transformação industrial (VTI) relativo às empresas que realizaram investimentos em algum tipo de controle ambiental correspondia a 34,1\% do VTI do país. Já em 2002, esse percentual subiu para $48,2 \%$, o que sugere que as empresas que fizeram investimentos ambientais são, em sua maioria, as grandes organizaçóes.

14 Vale ressaltar que essas relações não estabelecem uma causalidade entre as variáveis. 


\subsection{Esforço inovativo}

A presente seção realiza uma análise no que tange os esforços inovativos das empresas e sua relação com as IA. As tabelas analisadas trazem dados referentes às perguntas da Pintec 2008 correspondentes à seção "Atividades Inovativas" - que questionam as 37.808 firmas inovadoras da indústria de transformação sobre a importância (alta, média, baixa e não relevante) desses esforços - cruzados com a variável RIA.

TABELA 3

Distribuição das empresas da indústria de transformação que realizaram IA, por situação de redução do impacto ambiental, segundo tipos de atividade inovativa e importância

Brasil - 2008

\begin{tabular}{l|rr} 
& \multicolumn{2}{c}{ Em porcentagem } \\
\hline \multirow{2}{*}{ Tipos de atividade inovativa e importância } & \multicolumn{2}{c}{ Não } \\
\cline { 2 - 3 } P\&D & \multicolumn{1}{c}{ Sim } & 6,2 \\
Alta e média & 27,8 & 60,9 \\
Baixa e não desenvolveu & 32,9 & 67,1 \\
Total & & \\
Aquisição externa de P\&D & 2,1 & 2,0 \\
Alta e média & 30,9 & 65,0 \\
Baixa e não desenvolveu & 33,0 & 67,0 \\
Total & & 5,4 \\
Aquisição de outros conhecimentos externos & 5,4 & 61,7 \\
Alta e média & 27,5 & 67,1 \\
Baixa e não desenvolveu & 32,9 & \\
Total & & 57,1 \\
Aquisição de máquinas e equipamentos & 25,7 & 14,7 \\
Alta e média & 7,2 & 67,1 \\
Baixa e não desenvolveu & 32,9 & 36,7 \\
Total & & 30,4 \\
Treinamento & 22,3 & \\
Alta e média & 10,6 & \\
Baixa e não desenvolveu & 32,9 & \\
Total & & \\
\hline
\end{tabular}

Fonte: IBGE. Pesquisa de Inovação Tecnológica - Pintec 2008. Elaboração das autoras. 
$\mathrm{Na}$ Tabela 3, percebe-se que um baixo percentual de empresas relatou significativa importância para a realização de atividades inovativas relacionadas à geração de conhecimento, como $P \& D$, aquisição externa de $P \& D$ e aquisição de outros conhecimentos externos. Por outro lado, os esforços inovativos da firmas estão concentrados na aquisição de máquinas e equipamentos, como já foi comprovado por diversos estudos empíricos (STALLIVIERI; SOUZA 2008; BRITTO, 2004).

$\mathrm{Na}$ maioria das atividades inovativas, as empresas se concentram no quadrante de não realização de $\mathrm{IA}^{15}$ e baixa importância ou não desenvolvimento do esforço inovativo. Esse resultado confirma que a tendência brasileira de baixo esforço inovativo também está relacionada com a questão das IA, ou seja, as firmas da indústria de transformação brasileira, além de se engajarem relativamente pouco na geração de conhecimento, também realizam um baixo nível de IA.

Para complementar a análise da Tabela 3, faz-se necessário compreender as diferenças decorrentes de uma alta e baixa relevância dos esforços inovativos e o fato de a empresa ter realizado IA ou não, como é demonstrado na Tabela 4.

Um resultado interessante verificado refere-se ao item "aquisição de máquinas e equipamentos". Pela Tabela 3, observa-se que é nessa atividade que se concentram os esforços inovativos das empresas brasileiras. No entanto, ao se fazer uma análise proporcional, percebe-se que a realização desse esforço inovativo de maneira significativa não tem relação com a geração de IA. As proporçôes de empresas que realizaram ou não RIA são semelhantes independentemente da relevância dessa atividade inovativa (Tabela 4), o que mostra que não faz diferença, em termos de geração de IA, uma relevância alta ou baixa na aquisição de máquinas e equipamentos. Assim, pode-se afirmar que um foco nessa atividade não garante a introdução de IA.

No item "treinamento", 59\% (22,3\% mais 36,7\%) das empresas inovadoras declararam importância alta e média para esse esforço inovativo (Tabela 3). Entretanto, é interessante notar (Tabela 4) que as firmas que realizaram treinamento de maneira significativa fizeram, proporcionalmente, mais IA do que as que declararam baixa importância para esse esforço inovativo. Assim, pode-se afirmar que a realização de treinamento com alta e média relevância é mais importante para IA do que para inovaçôes que não reduziram os impactos ambientais.

15 Deve-se ressaltar que todos os resultados são para as empresas inovadoras, ou seja, o quadrante de não realização de IA significa que as firmas não geraram inovações que reduziram os impactos ambientais, mas realizaram algum tipo de inovação de produto e/ou processo. 
TABELA 4

Distribuição das empresas da indústria de transformação que realizaram IA, por situação de redução do impacto ambiental, segundo tipos de atividade inovativa e importância - total por grau de importância Brasil - 2008

\begin{tabular}{|c|c|c|c|}
\hline \multicolumn{4}{|c|}{ Em porcentagem } \\
\hline \multirow{2}{*}{ Tipos de atividade e importância } & \multicolumn{3}{|c|}{ RIA } \\
\hline & Sim & Não & Total \\
\hline \multicolumn{4}{|l|}{ P\&D } \\
\hline Alta e média & 45,0 & 55,0 & 100,0 \\
\hline Baixa e não desenvolveu & 31,4 & 68,6 & 100,0 \\
\hline \multicolumn{4}{|l|}{ Aquisição externa de P\&D } \\
\hline Alta e média & 50,6 & 49,4 & 100,0 \\
\hline Baixa e não desenvolveu & 32,2 & 67,8 & 100,0 \\
\hline \multicolumn{4}{|l|}{ Aquisição de outros conhecimentos externos } \\
\hline Alta e média & 50,4 & 49,6 & 100,0 \\
\hline Baixa e não desenvolveu & 30,8 & 69,2 & 100,0 \\
\hline \multicolumn{4}{|l|}{ Aquisição de máquinas e equipamentos } \\
\hline Alta e média & 32,9 & 67,1 & 100,0 \\
\hline Baixa e não desenvolveu & 33,0 & 67,0 & 100,0 \\
\hline \multicolumn{4}{|l|}{ Treinamento } \\
\hline Alta e média & 37,9 & 62,1 & 100,0 \\
\hline Baixa e não desenvolveu & 25,8 & 74,2 & 100,0 \\
\hline
\end{tabular}

Fonte: IBGE. Pesquisa de Inovação Tecnológica - Pintec 2008. Elaboração das autoras.

Esse resultado sugere que a criação de competências e qualificação dos funcionários está ligada à introdução de IA. O desenvolvimento e a utilização de produtos e processos novos normalmente requerem treinamento dos funcionários, mas o que se constata é que esse caráter é mais acentuado para o caso das IA, pois esse tipo de inovação pode envolver informação e conhecimento específicos que, muitas vezes, estão muito à frente da corrida tecnológica.

Segundo Williams e Markusson (2002), as atividades de treinamento fazem com que os funcionários fiquem mais interessados em influenciar decisóes na empresa. Se for permitido que os trabalhadores expressem suas ideias, isso aumenta o potencial para geração de inovações. Dessa forma, a capacitação dos funcionários 
gera maior conhecimento e aprendizado, o que pode influenciar também os aspectos ambientais da produção. Com base em outros estudos, os autores ainda afirmam que o treinamento é uma das atividades que as firmas mais utilizam para promover uma estratégia environmentally friendly, pois essa relação entre capacitação e IA está ligada à mudança da cultura corporativa de longo prazo.

Os itens "P\&D", "aquisição externa de P\&D" e "aquisição de outros conhecimentos externos" são caracterizados por um cenário de baixa importância ou não desenvolvimento dessas atividades. Assim, a maioria das empresas que realizaram IA não desenvolveu esses esforços inovativos de maneira significativa, o que mostra que a geração de IA não depende diretamente dessas atividades. Esse cenário é consequência do perfil inovador brasileiro, que, como foi dito, é muito baseado na aquisição de máquinas e equipamentos.

Desse modo, pode-se afirmar que uma alta importância dessas atividades não é uma condição sine qua non para investir em IA, o que sugere que as empresas podem tentar desenvolver IA por outras maneiras. Ao analisar diversos estudos empíricos, Williams e Markusson (2002) sugerem que as IA muitas vezes podem não requerer extensivas atividades de P\&D. Uma possível explicação é a predominância de tecnologias do tipo end-of-pipe, que, por terem um caráter incremental, normalmente não necessitam de atividades de $\mathrm{P} \& \mathrm{D}$ de maneira intensiva. Esse fato também pode estar relacionado à questão regulatória, que pode induzir mais a inovações do tipo end-of-pipe do que pollution-prevention.

Por outro lado, uma expressiva relevância das atividades de $P \& D$ pode aumentar significativamente a capacidade de as firmas realizarem IA. Pela análise da Tabela 4, são nesses três itens que um alto esforço inovativo faz mais diferença entre as empresas que inovaram ambientalmente ou não. Por exemplo, entre aquelas que declararam alta e média importância para $\mathrm{P} \& \mathrm{D}, 45 \%$ desenvolveram inovaçōes do tipo RIA, contra $31 \%$ das que declararam baixa importância e não desenvolvimento de P\&D, evidenciando que uma significativa importância dessas atividades inovativas está relacionada ao aumento da proporção de empresas que realizaram IA. ${ }^{16}$ Além disso, ainda pela Tabela 4, pode-se afirmar que realizar esforços inovativos relacionados à questão do conhecimento é mais importante para IA do que para as inovações que não diminuíram os danos ambientais.

16 Deve-se ressaltar o baixo percentual de empresas que declararam significativa importância para P\&D, aquisição externa de P\&D e aquisição de outros conhecimentos externos. No entanto, esses números não desconsideram os resultados analisados. Por outro lado, seria interessante que essas análises também fossem realizadas controlando por tamanho e capital de origem para que essas relações ficassem mais claras. Como essa análise não cabe ao escopo do estudo, fica a indicação para pesquisas futuras. 
Esse resultado pode ser consequência do fato de que a geração e introdução de IA, por serem algo relativamente novo nas estratégias empresariais, constituem um processo que está muito ligado à criatividade, criação de conhecimento, além de requerer diversas análises prévias para a introdução. Assim, muitas vezes, introduzir IA não é algo simples e, por isso, a realização de atividades de $\mathrm{P} \& \mathrm{D}$ pode influenciar e auxiliar as empresas na geração de IA. Vale ressaltar que não foram analisadas as características das firmas e sua relação com as atividades inovativas, mas, como há uma propensão de as empresas maiores investirem mais em $\mathrm{P} \& \mathrm{D}$, pode-se afirmar que existe um tripé P\&D - IA - empresas de maior porte.

Portanto, conclui-se que os esforços inovativos voltados para criação de conhecimento e construção de competências (treinamento) estão relacionados com as IA. Ou seja, essas atividades inovativas são elementos-chave para se compreender a visão sistêmica da inovação de maneira geral, mas elas tornam-se ainda mais relevantes quando se insere a questão ambiental. ${ }^{17}$

\subsection{Estratégias de cooperação}

Como a inovação é caracterizada por um processo coletivo que depende de interações para difusão do conhecimento, a cooperação entre os agentes envolvidos nas atividades inovativas são importantes canais de geração de conhecimento e aprendizado que auxiliam na formação de um Sistema Nacional de Inovação. Os diversos atores possuem diferentes competências e, por isso, a troca por meio da cooperação se torna essencial para as atividades inovativas, pois os agentes não inovam de maneira isolada, mas o fazem num contexto de um sistema de redes de relações diretas e indiretas (CASSIOLATO; STALLIVIERI, 2010).

Além disso, como parte do conhecimento que gera inovação emerge fora do sistema formal de P\&D, a busca de parceiros para cooperação torna-se relevante nas estratégias inovadoras das firmas. Assim, para compreender o comportamento inovativo das empresas, faz-se necessário analisar esses processos de aprendizado e acumulação de conhecimento que se dão por meio da cooperação e inter-relações entre esses agentes.

A presente seção toma como base os dados de "cooperação para inovação" da Pintec 2008 para fazer o cruzamento com a variável ambiental, com o objetivo de verificar quais os principais canais de cooperação utilizados pelas firmas que realizam

17 É interessante destacar a necessidade de estudos futuros para compreender melhor as relações das estratégias e esforços inovativos com as questões ambientais. 
IA. Vale ressaltar que a Pintec 2008 identifica como cooperação para inovação a "participação ativa da empresa em projetos conjuntos de P\&D e outros projetos de inovação com outra organização" (IBGE, 2010, p. 24). Entretanto, essa relação não gera, necessariamente, benefícios comerciais.

Segundo a Pintec 2008, entre as empresas inovadoras da indústria de transformação (37.808), aproximadamente 10,1\% declararam ter realizado atividades de cooperação. Diante disso, percebe-se que a estratégia de cooperação entre agentes, por mais importante que seja para o processo inovativo, ainda não está inserida na mentalidade e na prática da maioria das empresas. Esse resultado levanta a hipótese de que as firmas podem não buscar estabelecer cooperação pelo fato de essa ação ser vista como algo bastante complexo, pois envolve conflitos de interesse, capacidade de governança, risco, definição de modalidades de apropriação de conhecimento, etc. (MACULAN, 2010).

No questionário da Pintec 2008, as empresas foram solicitadas a relatar a importância (alta, média, baixa e não relevante) da cooperação com cada tipo de parceiro e o objeto de cooperação estabelecido. Primeiramente, verificou-se para quais parceiros foi declarado um maior percentual para alta e média importância da relação de cooperação. A Tabela 5 apresenta os resultados.

TABELA 5

Distribuiç̧ão das empresas da indústria de transformação que realizaram atividade de cooperação, por grau de importância, segundo parceiros

Brasil - 2008

\begin{tabular}{l|c|c}
\multicolumn{1}{c}{ Parceiros } & \multicolumn{2}{c}{ Emportância } \\
\cline { 2 - 3 } & Alta e média & $\begin{array}{c}\text { Baixa e não } \\
\text { relevante }\end{array}$ \\
\hline Fornecedores & 64,9 & 35,1 \\
Outra empresa do grupo & 59,3 & 40,7 \\
Clientes ou consumidores & 44,7 & 55,3 \\
Universidades ou institutos de pesquisa & 29,4 & 70,6 \\
Empresas de consultoria & 29,4 & 70,6 \\
Centros de capacitação profissional e assistência & & 73,3 \\
técnica & 26,7 & 76,7 \\
Instituições de testes, ensaios e certificações & 23,3 & 84,5 \\
Concorrentes & 15,5 & \\
\hline
\end{tabular}

Fonte: IBGE. Pesquisa de Inovação Tecnológica - Pintec 2008. Elaboração das autoras. 
De acordo com a Tabela 5, percebe-se que a cooperação com fornecedores é a relação mais importante para as firmas inovadoras. Em seguida, vem a cooperação com outras empresas do grupo e clientes e consumidores. As universidades e institutos de pesquisa aparecem somente em quarto lugar, evidenciando que as empresas ainda não buscam muito esse tipo de cooperação. Esse cenário converge com os resultados encontrados por Stallivieri e Souza (2008), no qual os autores mostram que a cooperação vertical (fornecedores e clientes) é a que mais se destaca na amostra de 1.206 empresas brasileiras.

Para verificar com quais parceiros foi declarada uma significativa importância para cooperação e sua relação com as inovações ambientais, os dados foram cruzados com a variável RIA (Tabela 6).

Como pode ser visto, o padrão relatado anteriormente se repete sem diferenças significativas para RIA, ou seja, o maior percentual de firmas corresponde àquelas que realizaram IA e relataram significativa importância para a cooperação com fornecedores, outra empresa do grupo e clientes ou consumidores. Além disso, em média, um número expressivo de empresas declarou baixa importância para a cooperação com os parceiros, considerando-se juntamente o desenvolvimento de IA. Esse resultado evidencia, mais uma vez, a pouca disponibilidade das empresas de realizarem atividades de cooperação tanto para inovaçôes de forma geral como para IA.

No entanto, esse resultado não mostra como uma estratégia de cooperação e interação entre agentes pode influenciar a geração ou não de IA. Assim, faz-se necessário verificar as diferenças entre realizar uma cooperação com alta e baixa importância e suas consequências sobre as IA. A Tabela 7 realiza essa comparação.

Como foi dito, a parceria com clientes e consumidores é uma das cooperaçôes mais relevantes para as inovaçôes de maneira geral. No entanto, pela Tabela 7 , verifica-se que essa parceria não tem relação com as IA, como pode ser visto pela manutenção dos percentuais de empresas que realizaram RIA independentemente da importância da cooperação. O mesmo ocorre com fornecedores. Esses resultados estão interligados, pois, se os consumidores não fazem exigências relacionadas à questão ambiental, diminuem os incentivos para os fornecedores se adequarem aos princípios da sustentabilidade. Mais uma vez, com base em diversos estudos empíricos, Williams e Markusson (2002) argumentam que as demandas ambientais das firmas sobre os fornecedores é bastante baixa. Além disso, eles afirmam que as inovaçôes radicais de processo requerem menor cooperação com fornecedores do que as inovaçôes radicais de produto. 
TABELA 6

Distribuição das empresas da indústria de transformação que realizaram IA, por situação de redução de impacto ambiental, segundo parceiros e importância da cooperação Brasil - 2008

\begin{tabular}{|c|c|c|}
\hline \multirow{3}{*}{ Parceiros e importância da cooperação } & \multicolumn{2}{|c|}{ Em porcentagem } \\
\hline & \multicolumn{2}{|c|}{ RIA } \\
\hline & Sim & Não \\
\hline \multicolumn{3}{|l|}{ Clientes ou consumidores } \\
\hline Alta a média & 23,1 & 21,6 \\
\hline Baixa e não relevante & 27,7 & 27,6 \\
\hline Total & 50,8 & 49,2 \\
\hline \multicolumn{3}{|l|}{ Universidades ou institutos de pesquisa } \\
\hline Alta a média & 19,4 & 10,0 \\
\hline Baixa e não relevante & 31,4 & 39,2 \\
\hline Total & 50,8 & 49,2 \\
\hline \multicolumn{3}{|c|}{ Centros de capacitação profissional e assistência técnica } \\
\hline Alta a média & 16,2 & 10,5 \\
\hline Baixa e não relevante & 34,6 & 38,7 \\
\hline Total & 50,8 & 49,2 \\
\hline \multicolumn{3}{|l|}{ Instituições de testes, ensaios e certificações } \\
\hline Alta a média & 14,8 & 8,6 \\
\hline Baixa e não relevante & 36,0 & 40,6 \\
\hline Total & 50,8 & 49,2 \\
\hline \multicolumn{3}{|l|}{ Fornecedores } \\
\hline Alta a média & 31,5 & 33,4 \\
\hline Baixa e não relevante & 19,3 & 15,8 \\
\hline Total & 50,8 & 49,2 \\
\hline \multicolumn{3}{|l|}{ Concorrentes } \\
\hline Alta a média & 9,4 & 6,2 \\
\hline Baixa e não relevante & 41,4 & 43,0 \\
\hline Total & 50,8 & 49,2 \\
\hline \multicolumn{3}{|l|}{ Outra empresa do grupo } \\
\hline Alta a média & 37,1 & 22,2 \\
\hline Baixa e não relevante & 20,4 & 20,3 \\
\hline Total & 57,5 & 42,5 \\
\hline \multicolumn{3}{|l|}{ Empresas de consultoria } \\
\hline Alta a média & 18,9 & 10,6 \\
\hline Baixa e não relevante & 31,9 & 38,6 \\
\hline Total & 50,8 & 49,2 \\
\hline
\end{tabular}

Fonte: IBGE. Pesquisa de Inovação Tecnológica - Pintec 2008. Elaboração das autoras. 
TABELA 7

Distribuição das empresas da indústria de transformação que realizaram IA, por situação de redução do impacto ambiental, segundo parceiros e importância da cooperação - total por grau de importância

Brasil - 2008

\begin{tabular}{|c|c|c|c|}
\hline \multirow{2}{*}{ Parceiros e importância da cooperação } & \multicolumn{3}{|c|}{ RIA } \\
\hline & Sim & Não & Total \\
\hline \multicolumn{4}{|l|}{ Clientes ou consumidores } \\
\hline Alta a média & 51,6 & 48,4 & 100,0 \\
\hline Baixa e não relevante & 50,1 & 49,9 & 100,0 \\
\hline Total & 50,8 & 49,2 & 100,0 \\
\hline \multicolumn{4}{|l|}{ Universidades ou institutos de pesquisa } \\
\hline Alta a média & 65,8 & 34,2 & 100,0 \\
\hline Baixa e não relevante & 44,5 & 55,5 & 100,0 \\
\hline Total & 50,8 & 49,2 & 100,0 \\
\hline \multicolumn{4}{|c|}{ Centros de capacitação profissional e assistência técnica } \\
\hline Alta a média & 60,7 & 39,3 & 100,0 \\
\hline Baixa e não relevante & 47,1 & 52,9 & 100,0 \\
\hline Total & 50,8 & 49,2 & 100,0 \\
\hline \multicolumn{4}{|l|}{ Instituições de testes, ensaios e certificações } \\
\hline Alta a média & 63,2 & 36,3 & 100,0 \\
\hline Baixa e não relevante & 46,9 & 53,1 & 100,0 \\
\hline Total & 50,8 & 49,2 & 100,0 \\
\hline \multicolumn{4}{|l|}{ Fornecedores } \\
\hline Alta a média & 48,5 & 51,5 & 100,0 \\
\hline Baixa e não relevante & 54,9 & 45,1 & 100,0 \\
\hline Total & 50,8 & 49,2 & 100,0 \\
\hline \multicolumn{4}{|l|}{ Concorrentes } \\
\hline Alta a média & 60,0 & 40,0 & 100,0 \\
\hline Baixa e não relevante & 49,1 & 50,9 & 100,0 \\
\hline Total & 50,8 & 49,2 & 100,0 \\
\hline \multicolumn{4}{|l|}{ Outra empresa do grupo } \\
\hline Alta a média & 62,6 & 37,4 & 100,0 \\
\hline Baixa e não relevante & 50,1 & 49,9 & 100,0 \\
\hline Total & 57,5 & 42,5 & 100,0 \\
\hline \multicolumn{4}{|l|}{ Empresas de consultoria } \\
\hline Alta a média & 64,0 & 36,0 & 100,0 \\
\hline Baixa e não relevante & 45,2 & 54,8 & 100,0 \\
\hline Total & 50,8 & 49,2 & 100,0 \\
\hline
\end{tabular}

Fonte: IBGE. Pesquisa de Inovação Tecnológica - Pintec 2008. Elaboração das autoras. 
De acordo com a Tabela 7, nota-se que, do total de empresas que relataram alta relevância para a cooperação com universidades e institutos de pesquisa, 65,8\% desenvolveram uma inovação do tipo RIA. Por outro lado, do total de empresas que declararam baixa importância para a cooperação com esse parceiro, somente 44,7\% realizaram RIA. Também é possível afirmar que uma alta relevância na cooperação com esses parceiros é mais importante para IA do que para as inovações que não utilizam tecnologias mais limpas.

Pelos dados da Pintec 2008, também pode-se verificar que o principal objeto de cooperação com universidades e institutos de pesquisa é P\&D, principalmente para o caso de introdução de RIA, o que confirma a relação entre universidades e institutos de pesquisa, P\&D e IA. Mais uma vez, o fator relevante é a criação de conhecimento e sua forte relação com as IA, em comparação com as inovações de forma geral. Como o conhecimento está no centro da dinâmica de desenvolvimento e difusão de inovações, as universidades e institutos de pesquisa são atores relevantes no processo inovativo em decorrência do seu caráter gerador dessa competência.

Esse mesmo cenário é encontrado para alguns parceiros, como empresas de consultoria e, em menor grau, instituições de testes, ensaios e certificaçôes. ${ }^{18}$ No caso de empresas de consultoria, como esse parceiro é um potencial gerador de conhecimento, ele é contratado por ser especializado em certos temas, o que pode auxiliar as empresas na implementação de IA. De acordo com os dados da Pintec 2008, as empresas de consultoria cooperam com as firmas, principalmente, nas atividades de treinamento e assistência técnica, o que sugere que esse parceiro, por ter expertise e serviços profissionais especializados, potencializa a implementação de IA por meio do conhecimento específico e da capacidade de ampliação das competências das empresas.

O parceiro instituições de testes, ensaios e certificações também aparece como relevante para as IA, o que pode estar relacionado à questão das certificações ambientais e testes de produtos ambientalmente sustentáveis. Ou seja, as firmas que realizam IA buscam certificações e testes para validar, qualificar e até aumentar a competitividade de seus produtos e processos "verdes".

18 A parceria com centros de capacitação profissional e assistência técnica, outra empresa do grupo e concorrentes também apresenta alguma relação com as IA, mas em menor intensidade. Nesses tipos de cooperação, seria interessante realizar tanto um estudo setorial quanto uma análise controlada pelo tamanho e capital de origem das firmas para verificar onde essas ligações estariam mais acentuadas. 
Ao realizar um cruzamento das análises das Tabelas 5 e 7 , pode-se constatar que as parcerias que geram as maiores relaçôes com a introdução de IA também são os tipos de cooperação que as firmas declararam menor importância. Ou seja, a maior parte da alta e média cooperação para a inovação de forma geral está concentrada nos parceiros que têm pouca influência na realização de IA.

Portanto, sabe-se que a cooperação tem uma influência significativa na atividade inovativa de maneira geral, mas os resultados mostram que essa relação se acentua no caso das IA. Isso sugere que as firmas que introduziram inovaçôes com redução dos impactos ambientais podem buscar parcerias justamente para isso, pois muitas vezes a empresa não tem técnicas nem conhecimento suficientes para introduzir esse tipo de inovação, que pode ter especificidades em decorrência do caráter de vanguarda desse conhecimento "ambiental". Por outro lado, pode-se argumentar que as firmas que realizam IA estão mais atentas às tendências de mercado e têm mais know-how das atividades inovativas de maneira geral, o que as leva a buscarem mais parceiros para cooperação, pois sabem que isso gera ganhos significativos para a empresa.

\subsection{Fontes de financiamento e subsídios}

Nesta seção, são analisadas as fontes de financiamento das IA e a relação destas com os diversos programas de apoio do governo às atividades inovativas. No questionário da Pintec 2008, a firma é solicitada a declarar o percentual dos dispêndios de acordo com as fontes de financiamento utilizadas. É analisado, aqui, somente o financiamento de atividades de $\mathrm{P} \& \mathrm{D}$, inclusive sua aquisição.

Para utilizar a mesma metodologia de cálculo da variável RIA, foi calculada uma média do percentual de dispêndios das firmas que declararam significativa importância para a redução de impacto ambiental para cada fonte de financiamento utilizada. O mesmo cálculo foi realizado para importância baixa e não relevante, com o objetivo de separar os dispêndios de acordo com as firmas que realizaram ou não IA. A Tabela 8 apresenta esses resultados. ${ }^{19}$

Primeiramente, pode-se verificar que grande parte das atividades de P\&D é financiada por recursos próprios. Entre os de terceiros, predomina a utilização de recursos públicos para o financiamento dessas atividades.

19 Vale ressaltar que, das 37.808 firmas inovadoras da indústria de transformação, 12.451 declararam que suas inovações reduziram o impacto ambiental. 
Em relação à comparação entre os gastos das empresas que indicaram ou não RIA, percebe-se que, para aquelas que declararam redução de impacto ambiental, diminui o percentual médio dos dispêndios com fontes próprias de financiamento e aumenta o de fontes públicas. Uma hipótese para tal resultado é que esse tipo de inovação pode ser mais cara, pois, muitas vezes, depende de tecnologias de ponta e, por isso, as firmas recorrem mais às fontes governamentais. Outra hipótese é a possibilidade de o governo ceder mais subsídios para projetos ambientalmente sustentáveis.

TABELA 8

Distribuição das empresas da indústria de transformação que realizaram IA por situação de redução de impacto ambiental, segundo fontes de financiamento de P\&D

Brasil - 2008

\begin{tabular}{l|r|r} 
& \multicolumn{2}{c}{ Em porcentagem } \\
\hline \multicolumn{1}{c}{ Fontes de financiamento de P\&D } & Sim & Não \\
\cline { 2 - 3 } Próprias & 81,3 & 90,3 \\
De terceiros - privadas (nacional e/ou estrangeiro) & 0,7 & 2,0 \\
De terceiros - público & 18,0 & 7,7 \\
Total & $\mathbf{1 0 0 , 0}$ & $\mathbf{1 0 0 , 0}$ \\
\hline
\end{tabular}

Fonte: IBGE. Pesquisa de Inovação Tecnológica - Pintec 2008. Elaboração das autoras.

Para complementar essa análise, é interessante verificar os diferentes programas de apoio governamental à inovação. Para isso, as empresas que responderam afirmativamente às perguntas da seção "Apoio do governo" do questionário da Pintec 2008 (7.938 firmas da amostra expandida) foram separadas entre as que realizaram ou não RIA.

O maior percentual de empresas que utilizaram algum programa de incentivo do governo está fortemente concentrado no financiamento para aquisição de máquinas e equipamentos, o que contrasta com um baixo percentual nos outros programas de apoio. Esse resultado era esperado, pois, como já foi dito, o esforço inovativo brasileiro está concentrado nessa atividade. A Tabela 10 apresenta os valores percentuais de acordo com cada programa governamental, com o objetivo de verificar os programas que possuem relação com RIA. 
TABELA 9

Distribuição das empresas da indústria de transformação que realizaram IA, por situação de redução de impacto ambiental, segundo programas de apoio do governo utilizados

Brasil - 2008

\begin{tabular}{l|c|c} 
& \multicolumn{2}{c}{ Rm porcentagem } \\
\hline \multicolumn{1}{c|}{ Programas de apoio do governo } & Sim & Não \\
\cline { 2 - 3 } Incentivos fiscais à P\&D e inovação tecnológica & 3,89 & 1,63 \\
Incentivo fiscal Lei de Informática & 5,10 & 3,77 \\
Subvenção econômica à P\&D e à inserção de pesquisadores & 1,77 & 0,81 \\
$\begin{array}{l}\text { Financiamento a projetos de P\&D e inovação tecnológica, } \\
\text { sem parceria com universidades ou institutos de pesquisa }\end{array}$ & 3,76 & 2,85 \\
$\begin{array}{l}\text { Financiamento a projetos de P\&D e inovação tecnológica, } \\
\text { em parceria com universidades ou institutos de pesquisa } \\
\text { Financiamento exclusivo para a compra de máquinas e }\end{array}$ & 2,45 & 1,56 \\
equipamentos utilizados para inovar & & 38,24 \\
$\begin{array}{l}\text { Bolsas oferecidas pelas fundações de amparo à pesquisa e } \\
\text { RHAE/ CNPq para pesquisadores em empresas }\end{array}$ & 30,24 & 0,94 \\
Aporte de capital de risco & 0,51 & 1,72 \\
\hline
\end{tabular}

Fonte: IBGE. Pesquisa de Inovação Tecnológica - Pintec 2008. Elaboração das autoras.

Os três programas que mais estão relacionados com RIA dizem respeito ao incentivo à atividade de $\mathrm{P} \& \mathrm{D}$, seja por subvenção econômica, financiamento de projetos ou incentivos fiscais. Essa evidência mostra, mais uma vez, que existe uma relação entre as atividades de P\&D e as IA..$^{20}$ Mais uma vez, vale ressaltar que um número muito pequeno de empresas utilizou esses programas, pois a maioria está focada no financiamento para compra de máquinas e equipamentos. Ou seja, apesar dos incentivos, uma parcela muito baixa das empresas utiliza os programas de apoio para atividades relacionadas à $\mathrm{P} \& \mathrm{D}$. Esse fato retrata o perfil inovador brasileiro que tem uma enorme dificuldade de desenvolvimento das atividades relacionadas a esse esforço inovativo.

20 Ou seja, as empresas que investem em P\&D também estão mais dispostas a fazer IA, o que reflete a questão da geração de conhecimento e sua relação com a introdução de inovações que utilizam tecnologias mais limpas. 
TABELA 10

Distribuição das empresas da indústria de transformação que realizaram IA, por situação de redução de impacto ambiental, segundo programas de apoio do governo utilizados - total por programa Brasil - 2008

\begin{tabular}{|c|c|c|c|}
\hline \multicolumn{4}{|c|}{ Em porcentagem } \\
\hline \multirow{2}{*}{ Programas de apoio do governo } & \multicolumn{3}{|c|}{ RIA } \\
\hline & Sim & Não & Total \\
\hline Incentivos fiscais à P\&D e inovação tecnológica & 70,5 & 29,5 & 100,0 \\
\hline Incentivo fiscal Lei de Informática & 57,5 & 42,5 & 100,0 \\
\hline Subvenção econômica à P\&D e à inserção de pesquisadores & 68,5 & 31,5 & 100,0 \\
\hline $\begin{array}{l}\text { Financiamento a projetos de P\&D e inovação tecnológica, } \\
\text { sem parceria com universidades ou institutos de pesquisa }\end{array}$ & 56,9 & 43,1 & 100,0 \\
\hline $\begin{array}{l}\text { Financiamento a projetos de P\&D e inovação tecnológica, } \\
\text { em parceria com universidades ou institutos de pesquisa }\end{array}$ & 61,0 & 38,0 & 100,0 \\
\hline $\begin{array}{l}\text { Financiamento exclusivo para a compra de máquinas e } \\
\text { equipamentos utilizados para inovar }\end{array}$ & 44,2 & 55,8 & 100,0 \\
\hline $\begin{array}{l}\text { Bolsas oferecidas pelas fundações de amparo à pesquisa e } \\
\text { RHAE/ CNPq para pesquisadores em empresas }\end{array}$ & 35,0 & 65,0 & 100,0 \\
\hline Aporte de capital de risco & 30,5 & 69,5 & 100,0 \\
\hline
\end{tabular}

Fonte: IBGE. Pesquisa de Inovação Tecnológica - Pintec 2008. Elaboração das autoras.

Como foi dito, o financiamento exclusivo para compra de máquinas e equipamentos para inovar é o programa em que se concentra o maior número de empresas. No entanto, pela análise da Tabela 10, percebe-se que a maior parte das empresas que utilizaram esse financiamento não declarou RIA. Esse resultado é complementar à Tabela 4, que mostra que a aquisição de máquinas e equipamentos não tem relação com a introdução de RIA.

\section{Conclusões}

O presente trabalho buscou avançar no debate sobre os determinantes das IA sob a ótica da teoria evolucionária, para verificar a existência ou não de uma convergência das estratégias inovativas das firmas brasileiras com as questôes ambientais. Com base nos dados da Pintec 2008 para as empresas inovadoras da indústria de trans- 
formação brasileira, o estudo analisou as características daquelas que adotaram IA e suas estratégias de cooperação, atividades inovativas e a questão dos financiamentos.

Como esperado, os dados evidenciaram que a introdução de IA está relacionada com o tamanho da empresa e com a origem estrangeira do capital, ou seja, fatores que remetem à questão da importância da inserção internacional.

Em relação às estratégias e aos esforços inovativos, verificou-se que não existe uma convergência com as questôes ambientais, pois esses esforços estão focados em elementos que têm pouca ou nenhuma relação com as IA (como é o caso da aquisição de máquinas e equipamentos, cooperação com clientes e fornecedores e programas de financiamento para aquisição de máquinas e equipamentos). Deve-se ressaltar que não se está afirmando que a aquisição de máquinas e equipamentos e a cooperação com clientes e fornecedores não geram IA. Apenas se enfatiza que realizar grandes esforços nesses pontos não faz tanta diferença em termos de geração de IA como outros elementos analisados. ${ }^{21}$

Por outro lado, os fatores relacionados à geração e difusão de conhecimento, aprendizado e fortalecimento das capacitações (atividades relacionadas à P\&D, treinamento, cooperação com universidades e institutos de pesquisa, etc.) têm menor importância nas estratégias das firmas, mas apresentaram significativa relação com as IA. Ou seja, esses esforços inovativos relacionados ao conhecimento são elementos-chave para se compreender a visão sistêmica da inovação de maneira geral, mas eles se tornam ainda mais relevantes quando se insere a questão ambiental.

Esses resultados enfatizam que as estratégias das firmas não convergem com a necessidade de se avançar rumo a um desenvolvimento menos agressivo ao meio ambiente. Assim, a estratégia defensiva da indústria brasileira de focar o esforço inovativo (e ambiental) na aquisição de máquinas e equipamentos reflete um cenário apenas de modernização tecnológica, em vez da geração de inovações que possuam uma ampla base de conhecimento, capazes de criar maiores sinergias tanto na esfera produtiva quanto na ambiental. Ou seja, esse cenário sugere que, no Brasil, as IA são introduzidas do exterior e incorporadas em máquinas e processos, refletindo muitas vezes as condições de pressão ecológica existentes em alguns países.

O fato de as IA estarem relacionadas com a questão do conhecimento e do fortalecimento das competências sugere que essas inovações se encontram na fron-

21 Entretanto, mais uma vez, os limites da Pintec podem esconder uma relação maior desses elementos com as IA, pois, além de a Pintec não captar de maneira satisfatória o próprio processo inovativo, pode ser que haja uma distorção no seu entendimento de inovação que reduz os impactos ambientais. Tais limites ainda se confundem com a falta de percepção das empresas sobre o que vem a ser uma inovação ambiental. 
teira do conhecimento e, por isso, requerem capacidades específicas que as firmas não dominam completamente. Nesse sentido, Kemp e Soete (1990) afirmam que uma das dificuldades do desenvolvimento da IA é a falta de conhecimento e informação sobre essas tecnologias dentro das empresas e, por isso, elas procuram essas competências nas universidades e institutos relacionados à criação e ao fortalecimento dessas capacidades. No entanto, o fato de ser um conhecimento específico não significa que ele seja extremamente complexo, pois o aprendizado é uma nova combinação de conhecimentos e, portanto, a utilização deste depende da capacidade de absorção e das práticas e estruturas de cada firma. Assim, existem diversas janelas de oportunidades que as empresas brasileiras podem explorar por meio da difusão de conhecimento tácito adequado às suas realidades. Desse modo, pode-se afirmar que a adoção de IA depende mais de fatores organizacionais do que da falta de conhecimento disponível no sistema como um todo (WILLIAMS; MARKUSSON, 2002).

Diante disso, pode-se afirmar que, para caminhar rumo a um desenvolvimento mais sustentável, é necessário priorizar políticas que incentivem a adoção de esforços inovativos, atividades de cooperação e programas de apoio do governo que estão "à margem" das estratégias inovativas das firmas brasileiras. Assim, as evidências apontadas no presente trabalho vão de acordo com as sugeridas por Freeman (1996), para quem as políticas ambientais deveriam incorporar a questão inovativa, direcionando programas para fortalecimento da cooperação das firmas com universidades, encorajando empresas a adquirirem certificaçóes ambientais e concedendo incentivos para atividades de treinamento dentro das empresas para promover a qualificação dos trabalhadores.

Portanto, uma mudança para um paradigma tecnoeconômico "verde" requer transformações que vão além de mudanças incrementais na tecnologia (FREEMAN, 1996; FORAY; GRÜBLER, 1996; WILLIAMS; MARKUSSON, 2002). Não se está negando a importância das IA de caráter incremental, mas as inovaçóes radicais e tecnologias do tipo pollution-prevention têm o potencial de gerar um maior encadeamento no sistema econômico, social e ambiental. Além disso, para essa mudança, é necessário que as políticas ambientais e tecnológicas sejam convergentes. Se atuarem de forma conjunta, essas políticas podem gerar incentivos para redução de emissão por parte das empresas, pois estas passariam a buscar caminhos tecnológicos alternativos para reduzir os danos ambientais. As políticas tecnológicas podem ter um menor custo caso sejam utilizadas como complementares e não como substitutas às políticas ambientais (JAFFE et al., 2004). Na ausência da aplicação dessas políticas 
de maneira sincronizada, as empresas têm pouco incentivo para mudar para uma trajetória tecnológica mais sustentável. Mais uma vez, como já havia afirmado por Freeman (1996, p. 36):

The use of science and technology policies to achieve environmental goals constitutes a new focus for technology policy [...] Environmental projects will need to combine procurement with many other policies in order to have pervasive effects on the entire structure of production and consumption within an economy. The pervasive character of new mission-oriented projects to meet environmental goals calls for a systemic approach to policy.

Por fim, é importante lembrar que o estudo tem importantes limitaçóes no que tange à utilização de uma única base de dados que não capta de forma satisfatória a capacidade inovativa da indústria brasileira e tampouco evidencia de maneira direta a questão ambiental dentro das firmas. Nesse sentido, seria interessante que, no futuro, a Pintec avançasse nas questóes relacionadas às IA, na tentativa de captar o tipo de inovação ambiental e a real motivação da introdução dessas inovaçôes por parte das empresas (se foram motivadas somente por uma necessidade de redução de custos, se foram introduzidas por uma responsabilidade ambiental das empresas ou se a firma foi obrigada a introduzir a IA por uma regulação).

Entretanto, pela utilização de dados novos relacionados à questão ambiental e inovativa das empresas, pode-se afirmar que o presente trabalho buscou dar uma importante contribuição para o debate rumo a um desenvolvimento mais sustentável. Desse modo, este estudo torna-se ainda relevante por dois fatores centrais: pelo fato de o debate ser bastante incipiente, com relativamente poucas pesquisas de âmbito nacional e uma grande precariedade de dados disponíveis; e pela crescente importância estratégica das tecnologias que reduzem os danos ambientais no cenário geopolítico mundial. Por isso, faz-se necessário que sejam realizados outros estudos sobre as questôes relacionadas às IA (principalmente os que captem de alguma maneira as especificidades setoriais e individuais), visando compreender melhor a natureza desses fatores para elaborar políticas públicas que realmente influenciem os agentes a tornar os processos produtivos mais limpos. 


\section{Referências bibliográficas}

ANDERSEN, M. M. An innovation system approach to eco-innovation - Aligning policy rationales. In: The Greening of Policies - Interlinkages and Policy Integration Conference. Anais eletrônicos... Berlim, 2004. Disponível em: <http://www.cgiar-ilac.org/files/andersen_ innovation.pdf>. Acesso em: 23 maio 2013.

ARUNDEL, A.; KEMP, R.; PARTO, S. Indicators for environmental innovation: what and how to measure. In: MARINOVA, D.; ANNANDALE, D.; PHILIMORE, J. (Eds.). International handbook on environment and technology management. Cheltenham: Edward Elgar, 2007, p. 324-339.

BARCELlOS, F. C.; OLIVEIRA, J. C.; CARVALHO, P. G. Investimentos ambiental em indústrias sujas e intensivas em recursos naturais e energia. Revista Iberoamericana de Economia Ecológica, v. 12, p.33-50, 2009.

BRITTO, J. Cooperação tecnológica e esforços inovativos na indústria brasileira: um estudo exploratório a partir da PINTEC. In: IX Encontro Nacional de Economia Política da SEP, 2004, Anais... Uberlândia-MG, 2004.

CASSIOLATO, J. E.; LASTRES, H. M. M. Discussing innovation and development: Converging points between the Latin American school and the innovation systems perspective? 2008. The Global Network for Economics of Learning, Innovation, and Competence Building System, 2008 (Globelics working papers series, n. 08-02).

CASSIOLATO, J. E.; STALLIVIERI, F. Indicadores de inovação: dimensões relacionadas à aprendizagem. In: CGEE (Org.). Bases conceituais em pesquisa, desenvolvimento e inovação: implicações políticas no Brasil. 1 $1^{\text {a }}$ ed. Brasília: Centro de Gestôes e Estudos Estratégicos, v. 1, 2010, p. 119-163.

CASSIOLATO, J. E.; STALLIVIERI, F.; RAPINI, M.; PODCAMENI, M. G. Indicadores de inovação: uma análise crítica para os BRICS. BRICS Project: A competitive study of the national innovation systems of Brazil, Rusia, India, China and South Africa. 2008 (Research paper 02/08).

CASSIOLATO, J. E.; PAGOLA, C.; LASTRES, H. M. M. Technical change and structural inequalities: converging approaches about problems of underdevelopment. In: DRECHSLER, W.; REINERT, E.; KATTEL, R. (Orgs.). Techno-economic paradigms: essays in honour of Carlota Perez. London: Anthgem Press, 2009, p. 51-65.

CORAZZA, R. I. Inovação tecnológica e demandas ambientais: notas sobre o caso da indústria brasileira de papel e celulose. Dissertação (Mestrado em Política Científica e Tecnológica). Campinas: DPCT/Unicamp, 1996. 
. Gestão ambiental e mudanças da estrutura organizacional. RAE eletrônica, v. 2, n. 2, 2003, p. 1 .

DOSI, G. Technological paradigms and technological trajectories: a suggested interpretation of the determinants and directions of technical change. Research Policy, v. 11, n. 3, p. 147162, junho 1982 .

DINIZ, M. J.; DINIZ, M.; OLIVEIRA JUNIOR, J. N. A introdução de inovações ambientais afeta o desempenho da indústria? Um estudo empírico para o Polo Industrial de Manaus (2000-2006). In: V Encontro Nacional da Anppas. Anais... Florianópolis, 2010.

EUROPEAN COMMISSION. Stimulating technologies for sustainable development: an environmental technologies action plan for the European Union. Communication from the commission to the council and the European parliament. Bruxelas, 2004.

FERRAZ, C; SEROA DA MOTA, R. Regulação, mercado ou pressão social? Os determinantes do investimento ambiental na indústria. In: XXIX Encontro Nacional de Economia. Anais... Rio de Janeiro, 2001.

FORAY, D.; GRÜBLER, A. Technology and the environment: an overview. Technological Forecasting and Social Change, v. 53, n. 1, p. 3-13, 1996.

FOXON, T.; ANDERSEN, M. M. The greening of innovation systems for eco-innovation - towards an evolutionary climate mitigation policy. In: Druid Summer Conference. Anais eletrônicos... Copenhagen, 2009. Disponível em: <http://www2.druid.dk/conferences/ viewpaper.php?id=500463\&cf=32>. Acesso em: 20 maio 2013.

FREEMAN, C. The greening of technology and models of innovation. Technological Forecasting and Social Change, v. 53, p. 27-39, 1996.

FRONDEL, M.; HORBACH, J.; RENNINGS, K. What triggers environmental management and innovation? Empirical evidence for Germany. RWI, 2004 (Discussion paper, n. 15).

HORBACH, J. Determinants of environmental innovation - New evidence from German Panel Data Source. Research Policy, v. 37, n. 1, p.163-173, 2006.

IBGE. Pesquisa de Inovação Tecnológica - PINTEC 2008. Rio de Janeiro: IBGE, 2010. Disponível em: <http://www.ibge.gov.br/home/estatistica/economia/industria/pintec/2008/ pintec2008.pdf>. Acesso em: jan. 2010.

Pesquisa de Inovação Tecnológica - PINTEC 2005. Rio de Janeiro: IBGE, 2007.

Disponível em: <http://www.ibge.gov.br/home/estatistica/economia/industria/pintec/2005/ pintec2005.pdf>. Acesso em: fev. 2011 
Julia Mello de Queiroz, Maria Gabriela von Bochkor Podcameni

. Pesquisa de Inovação Tecnológica - PINTEC 2003. Rio de Janeiro: IBGE, 2005. Disponível em: <http://www.ibge.gov.br/home/estatistica/economia/industria/pintec/2003/ pintec2003.pdf>. Acesso em: fev. 2011.

JAFFE, A.; NEWELL, R.; STAVINS, R. A tale of two market failures: technology and environmental policy. Washington DC: RFF, 2004 (Discussion paper, 04-38).

KEMP, R.; ANDERSEN, M. M. Strategies for eco-efficiency innovation. Strategy paper for the Informal Environmental Council Meeting. Maastricht, Holanda, July 2004.

KEMP, R.; FOXTON, T. Typology of eco-innovation (MEI project). Bruxelas, 2007. Disponível em: <http://www.merit.unu.edu/MEI>. Acesso em: 02 jan. 2013.

KEMP, R; PEARSON, P. Final report of Measuring Eco-innovation (MEI project). Bruxelas, 2007. Disponível em: <http://www.merit.unu.edu/MEI>. Acesso em: 27 maio 2013.

KEMP, R.; SOETE, L. Inside the 'green box': on the economics of technological change and the environment. In: FREEMAN, C.; SOETE, L. (Eds.). New explorations in the economics of technological change. London: Pinter Publishers, 1990, p. 245-257.

KUNH, T. The structure of scientific revolutions. $3^{\text {a }}$ ed. Chicago: The University of Chicago Press, 1962.

LUSTOSA, M. C. J. Inovação e meio ambiente no enfoque evolucionista: o caso das empresas paulistas. In: XXVII Encontro Nacional da Anpec Anais... Belém-PA, 1999.

MACULAN, A. M. A importância das interações para a inovação e a busca por indicadores. In: CGEE (Orgs.). Bases conceituais em pesquisa, desenvolvimento e inovação: implicações políticas no Brasil. 1ª ed. Brasília: Centro de Gestões e Estudos Estratégicos, v. 1, 2010, p. 165-186.

MAZZANTI, M.; ZOBOLI, R. Examining the factors influencing environmental innovations. FEEM, 2006 (Working paper, n. 20).

NELSON. R. R.; WINTER, S. G. An evolutionary theory of economic change. Cambridge: Harvard University Press, 1982.

NEVES, F. M.; AGUILAR FILHO, H. A. de. Dos paradigmas científicos aos tecnológicos: consideraçôes sobre o uso de uma analogia. Revista Economia Ensaios, v. 26, n. 2, p. 23-32, jan./jun. 2012.

OLTRA, V. Environmental innovation and industrial economics: the contribution of evolutionary economics. DIME, 2008 (Working papers on environmental innovation, n. 7).

PEREZ, C. Technological revolutions and techno-economic paradigms. Cambridge Journal of Economics, v. 34, n. 1, p. 185-202, Jan. 2009. 
PODCAMENI, M. G. B. Meio ambiente, inovação e competitividade: uma analise da indústria de transformação brasileira com ênfase no setor de combustível. Dissertação (Mestrado). Rio de Janeiro, Instituto de Economia, UFRJ, 2007.

PODCAMENI, M. G. B.; QUEIROZ, J. M.; CASSIOLATO, J. E.; SOARES, M. C. Innovation systems, development and sustainability: a new productive paradigm? Evidences from Brazil. In: 9th Globelics International Conference. Anais... Buenos Aires, 2011.

PORTER, M.; VAN DER LINDE, C. Verde e competitivo - Acabando com o impasse. In: PORTER, M. E. Competição: estratégias competitivas essenciais. Rio de Janeiro: Editora Campus, 1995, p. 371-397.

RENNINGS, K. Redefining innovation: eco-innovation research and the contribution from ecological economics. Ecological Economics, v. 32, p. 319-332, 2000.

REHFELD, K. M.; RENNINGS, K.; ZIEGLER, A. Integrated product policy and environmental product innovations: an empirical analysis. Center for European Economic Research, 2007 (Discussion paper, n. 04-71).

ROMEIRO, A. R.; SALLES FILHO, S. L. Dinâmica de inovaçōes sob restrição ambiental. In: ROMEIRO, A. R.; PHILIP, B. (Orgs.). Economia do meio ambiente: teoria política e a gestão de espaços regionais. $1^{\text {a }}$ ed. Campinas: Unicamp, v. 1, 1997, p. 85-124.

STALLIVIERI, F.; SOUZA, G. J. Processos de aprendizagem e cooperação: uma análise exploratória da influência sobre o desempenho inovativo. Economia Selecta, v. 9, n. 4, p. 151-182, dez. 2008.

STERN, N. The economics of climate change: the stern review. Cambridge: Cambridge University Press, 2007.

VINHA, V. A convenção do desenvolvimento sustentável e as empresas eco-comprometidas. Tese (Doutorado em Desenvolvimento, Agricultura e Sociedade). Rio de Janeiro, Instituto de Ciências Humanas e Sociais, Universidade Federal Rural do Rio de Janeiro, 1999.

WILLIAMS, R.; MARKUSSON, N. Knowledge and environmental innovations. In: Blueprint Workshop on Environmental Innovation Systems. Bruxelas, Jan. 2002.

YOUNG, C. E. F.; LUSTOSA, M. C. J.; ANDRADE PEREIRA, A.; ALMEIDA, J. C. Comércio e meio ambiente. Relatório de Pesquisa - Redipea. Rio de Janeiro: IE/UFRJ, 2001.

YOUNG, C. E. F.; QUEIROZ, J. M.; ROCHA, E. R. P. Avaliação dos critérios de sustentabilidade dos financiamentos apoiados pelos Fundos Constitucionais Brasileiros. 2009. 
Julia Mello de Queiroz, Maria Gabriela von Bochkor Podcameni

ENDEREÇOS PARA CORRESPONDENCIA

Julia Mello de Queiroz-julia.queiroz@funbio.org.br

Funbio - Fundo Brasileiro para Biodiversidade

Rua Voluntários da Pátria, 286, $5^{\circ}$ andar, Botafogo

22270-014 - Rio de Janeiro (RJ), Brasil

Maria Gabriela Von Bochkor Podcameni - gabriela.podcameni@gmail.com Instituto de Economia/UFRJ

Avenida Pasteur, 250, salas 104 e 107, Urca

22290-240 - Rio de Janeiro (RJ), Brasil

224 Revista Brasileira de Inovação, Campinas (SP), 13 (1), p. 187-224, janeiro/junho 2014 